\title{
Spectroscopic properties of two highly substituted PAH heteroanalogs: octakis(pyrazol-1-yl)naphthalene and octakis (3,5-dimethylpyrazol-1-yl)naphthalene
}

\author{
C. Escolastico, ${ }^{\dagger}$ M. A. Torres, ${ }^{\dagger}$ M. D. Santa Maria, ${ }^{\dagger}$ R. M. Claramunt, ${ }^{*}{ }^{\dagger}$ \\ N. Jagerovic, ${ }^{\ddagger}$ J. Elguero, ${ }^{\ddagger}$ and R. Sastre ${ }^{\ddagger}$ \\ Departamento de Quimica Organica y Biologi, Facultad de Ciencias, UNED, \\ Senda del Rey, 9,E-28040 Madrid, Spain, and Centro de Quimica Organica Manuel Lora- \\ Tamayo, \\ CSIC, Juan de la Cierva, 3, E-28006 Madrid, Spain \\ E-mail: rclaramunt@ccia.uned.es
}

(received 31 Jan 00; accepted 21 Sep 00; published on the web 29 Sep 00)

\begin{abstract}
Two heteroanalogs of octaphenylnaphthalene, octakis(pyrazol-1-yl)naphthalene and octakis(3,5dimethylpyrazol-1-yl)naphthalene have been prepared and fully characterized by NMR $\left({ }^{1} \mathrm{H}\right.$ and $\left.{ }^{13} \mathrm{C}\right)$. Although they are very insoluble in ordinary solvents, such as ethanol and ethyl acetate, absorption and emission spectra were recorded. These experiments show that the new compounds behave photophysically like other highly substituted naphthalenes.
\end{abstract}

Keywords: Octakis(pyrazol-1-1)naphthalenes, fluorescence, poly cyclic aromatic hydrocarbons 


\section{Introduction}

Polycyclic aromatic hydrocarbons (PAHs) such as octaphenylnaphthalene and decaphenylanthracene exhibit fluorescene emission and are capable of electrogenerated chemiluminescence [1-3]. This behaviour has been explained by the high degree of substitution on these compounds together with the fluxional nature of the phenyl substituents [3].

Our purpose has been to investigate two new heteroanalogs of octaphenylnaphthalene, the octakis(pyrazol-1-yl)naphthalene (OPzN) and octakis(3,5-dimethylpyrazol-1-yl)naphthalene $\left(\mathrm{OMe}_{2} \mathrm{PzN}\right)$, in order to study the effect produced on these interesting properties when phenyl groups are replaced by pyrazol-1-yl or 3,5-dimethylpyrazol-1-yl residues.

\section{Synthesis}

\section{Octakis(pyrazol-1-yl)naphthalene (OPzN).}

$0.5 \mathrm{~g}$ (7.3 mmol) of pyrazole in $5 \mathrm{~mL}$ of anhydrous THF were placed in a three-necked round bottomed flask provided with a reflux condenser, argon atmosphere and magnetic stirring. Then, $0.29 \mathrm{~g}(7.3 \mathrm{mmol})$ of $\mathrm{NaH}(60 \%$ oil dispersion) were added and the reaction mixture was heated to $65{ }^{\circ} \mathrm{C}$ for $1 \mathrm{~h}$. After cooling down at room temperature, $0.25 \mathrm{~g}(0.92 \mathrm{mmol})$ of octafluoronaphthalene were added and the mixture was heated under reflux for $2 \mathrm{~h}$. Compound $\mathrm{OPzN}$ precipitated from the reaction mixture, was filtered off, washed with water and purified by column chromatography using $\mathrm{CH}_{2} \mathrm{Cl}_{2} /$ ethanol 9:1 (yield 80\%). mp (by DSC) $=348{ }^{\circ} \mathrm{C}$ (dec.) ( $\mathrm{CH}_{2} \mathrm{Cl}_{2}$ /hexane). Anal. $\mathrm{C}_{34} \mathrm{H}_{24} \mathrm{~N}_{16} \cdot 1 \mathrm{H}_{2} \mathrm{O}$; Calc.(\%): $\mathrm{C} 60.52 ; \mathrm{H} 3.89 ; \mathrm{N} 33.21$ Found (\%): $\mathrm{C}$ 60.56; H 3.84; N 32.92; MS, m/z: 657 (M+H, 71.1), 154 (100). IR (KBr) : 3140, 3100, 3020, $1595,1515,1460,1390,1325,1200,1115,1095,1085,1075,1040,940,920,910,890,860$, $850,810,790,740,670,650,640,615 \mathrm{~cm}^{-1}$. 


\section{Octakis(3,5-dimethylpyrazol-1-yl)naphthalene $\left(\mathrm{OMe}_{2} \mathrm{PzN}\right)$.}

Solvent DMF, $18 \mathrm{~h}$ reflux, purified by column chromatography using $\mathrm{CH}_{2} \mathrm{Cl}_{2}$ /ethanol 95:5. (Yield 65\%). mp. 267-269 ${ }^{\circ} \mathrm{C}\left(\mathrm{CH}_{2} \mathrm{Cl}_{2} /\right.$ hexane). Anal. $\mathrm{C}_{50} \mathrm{H}_{56} \mathrm{~N}_{16}$; Calc.(\%): C 68.17; H 6.41; N 25.44 Found (\%): C 68.09; H 6.38; N 24.70; MS, m/z: 881 (M+H, 100). IR (KBr):2980, 2920, 2860, 1595, 1555, 1470, 1420, 1380, 1360, 1330, 1285, 1255, 1220, 1130, 1100, 1060, 1040, $1020,975,935,805,775,725,680,660,640,600 \mathrm{~cm}^{-1}$

\section{Absorption and fluorescence measurements}

Fluorescence spectra were recorded on a Perkin Elmer LS50B spectrometer while UV-visible spectra were recorded on a Perkin Elmer Lambda 16 spectrometer. Absolute ethanol (99.8\%, Panreac, UV-IR spectroscopic grade) and ethyl acetate (99.8\%, Sigma-Aldrich, HPLC grade) were used without further purification.

The excitation wavelengths used for the emission spectra were determined from the absorption spectra data. Both compounds are sparingly soluble in ethanol. The spectra correspond to saturated solutions obtained after sonication.

\section{Results and Discussion}

\section{Synthesis}

$\mathrm{OPzN}$ and $\mathrm{OMe}_{2} \mathrm{PzN}$ have been prepared by reacting octafluronaphthalene with pyrazole and 3,5-dimethylpyrazole anions, respectively (Scheme 1). We already applied successfully this method to obtain hexakis-azolyl-benzenes from hexafluorobenzene [4-7]. 


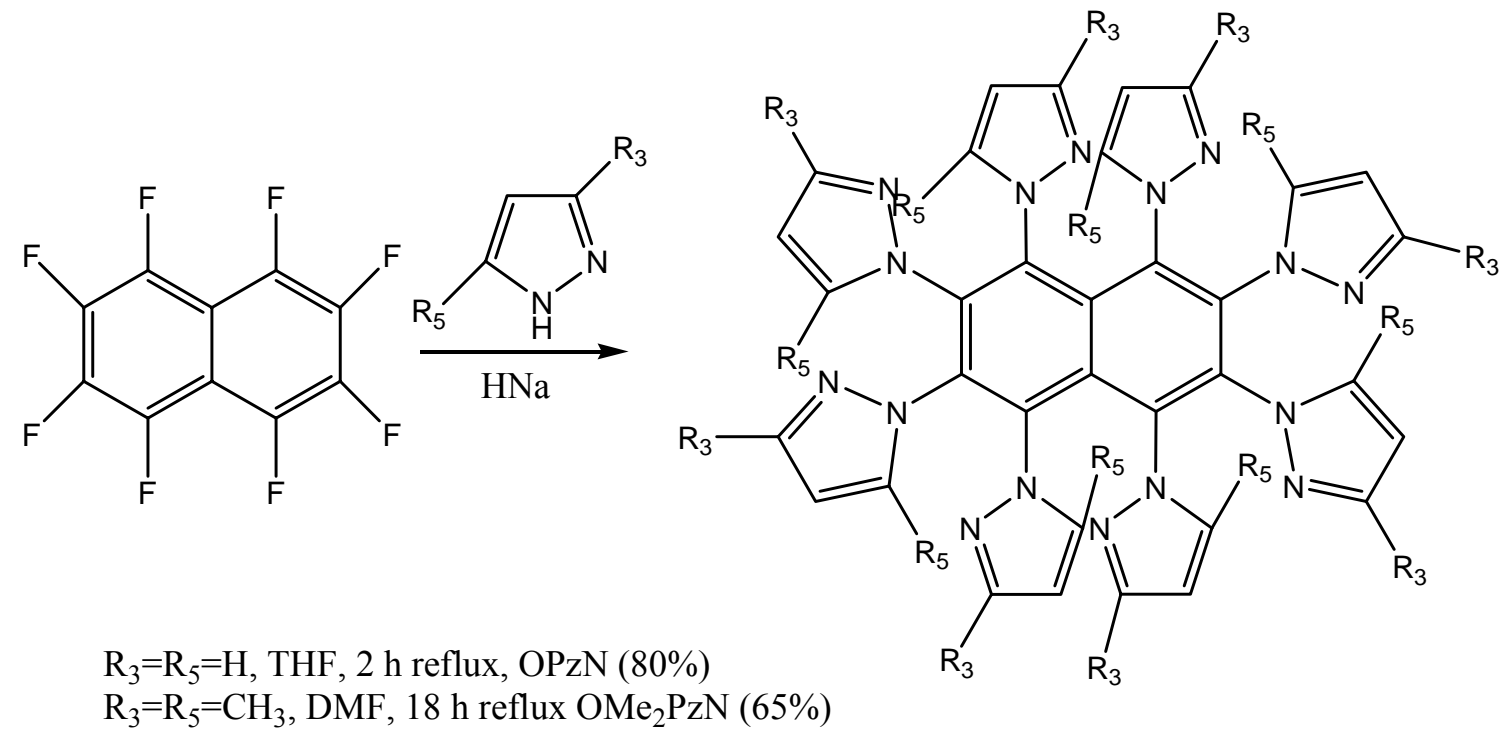

\section{Scheme 1}

\section{${ }^{1} \mathrm{H}$ and ${ }^{13} \mathrm{C}$ NMR studies}

These molecules, by reason of symmetry, have only two sets of signals besides the isochronous carbon atoms $\mathrm{C}-4 \mathrm{a}$ and $\mathrm{C}-8 \mathrm{a}$ : those belonging to the peri positions 1, 4, 5, 8 (Pz-1 or $\mathrm{Me}_{2} \mathrm{Pz}-1$ : C-1, N-1', N-2', H-3', H-4', H-5', C-3', C-4', C-5', Me-3' and Me-5') and those belonging to the other four positions 2, 3, 6, 7 (Pz-2 or Me 2 Pz-2: C-2, N-1", N-2", H-3", H-4", H-5", C-3", C-4", C-5", Me-3" and Me-5"). 
Table $1 .{ }^{15} \mathrm{~N},{ }^{13} \mathrm{C}$ and ${ }^{1} \mathrm{H}-\mathrm{NMR}$ chemical shifts in ppm and ${ }^{1} \mathrm{H}-{ }^{13} \mathrm{C}$ and ${ }^{1} \mathrm{H}-{ }^{1} \mathrm{H}$ coupling constants of octakis(pyrazol-1-yl)naphthalene (OPzN) and octakis(3,5-dimethylpyrazol-1-yl)naphthalene $\left(\mathrm{OMe}_{2} \mathrm{PzN}\right)$ in $\mathrm{CDCl}_{3}$.

Compound OPzN

\begin{tabular}{|c|c|c|c|c|c|}
\hline & Position & ${ }^{15} \mathrm{~N} /{ }^{13} \mathrm{C}$ & $J\left({ }^{1} \mathrm{H}-{ }^{13} \mathrm{C}\right)$ & ${ }^{1} \mathrm{H}$ & $J\left({ }^{1} \mathrm{H}-{ }^{1} \mathrm{H}\right)$ \\
\hline & N-1' & -179.0 & --- & ---- & --- \\
\hline & N-2' & -67.5 & ---- & ---- & ---- \\
\hline & C-3' & 141.4. & ${ }^{1} J=186.5$ & 7.31 & ${ }^{3} J=1.7^{\mathrm{a}}$ \\
\hline & & & $\begin{array}{l}{ }^{2} J=5.8 \\
{ }^{3} J=8.5\end{array}$ & & \\
\hline \multirow{10}{*}{$\begin{array}{l}\text { Positions } \\
1,4,5,8\end{array}$} & C-4' & 106.9 & ${ }^{1} J=178.4$ & 5.75 & ${ }^{3} J=1.7^{\mathrm{a}}$ \\
\hline & & & $\begin{array}{l}{ }^{2} J=10.2 \\
{ }^{2} J=8.6\end{array}$ & & ${ }^{3} J=2.4^{\mathrm{a}}$ \\
\hline & C-5' & 133.4 & ${ }^{1} J=192.4$ & 6.98 & ${ }^{3} J=2.4^{\mathrm{a}}$ \\
\hline & Me-3' & ---- & & ---- & \\
\hline & Me-5' & ---- & & ---- & \\
\hline & N-1" & -184.0 & ---- & ---- & \\
\hline & N-2" & -70.9 & ---- & ---- & \\
\hline & C-3" & 141.1 & ${ }^{1} J=186.9$ & 7.33 & ${ }^{3} J=1.9$ \\
\hline & & & ${ }^{2} J=5.8$ & & ${ }^{4} J=0.5$ \\
\hline & & & ${ }^{3} J=8.3$ & & \\
\hline \multirow{8}{*}{$\begin{array}{l}\text { Positions } \\
2,3,6,7\end{array}$} & C-4" & 106.8 & ${ }^{1} J=178.7$ & 6.02 & ${ }^{3} J=1.9$ \\
\hline & & & $\begin{array}{l}{ }^{2} J=10.3 \\
{ }^{2} J=86\end{array}$ & & ${ }^{3} j=2.4$ \\
\hline & C-5" & 132.0 & $\begin{array}{l}J-0.0 \\
{ }^{1} J=191.2\end{array}$ & 6.91 & ${ }^{3} J=2.4$ \\
\hline & & & ${ }^{2} J=9.3$ & & \\
\hline & & & ${ }^{3} J=4.6$ & & \\
\hline & Me-3" & ---- & & ---- & \\
\hline & Me-5" & ---- & & ---- & \\
\hline & C-1 & 136.8 & & ---- & \\
\hline \multirow[t]{5}{*}{ Naphthalene } & C-2 & 135.8 & & ---- & \\
\hline & C-4a,8a & 129.5 & & ---- & \\
\hline & & ${ }^{15} \mathrm{~N} /{ }^{13} \mathrm{C}$ & $J\left({ }^{1} \mathrm{H}^{-13} \mathrm{C}\right)$ & $\begin{array}{l}\text { OMe2PzN } \\
{ }^{1} \mathrm{H}\end{array}$ & \\
\hline & N-1' & -182.9 & ---- & & \\
\hline & N-2' & -74.0 & ---- & & \\
\hline
\end{tabular}


Table 1. Continued

\begin{tabular}{|c|c|c|c|c|}
\hline & C-3' & 148.9 & ${ }^{2} J=6.3$ & ---- \\
\hline & & ${ }^{2} J=6.3$ & & \\
\hline Position & C-4' & 105.4 & ${ }^{1} J=172.6$ & 5.31 \\
\hline $1,4,5,8$ & & & ${ }^{3} J=3.3$ & \\
\hline & & & ${ }^{3} J=3.3$ & \\
\hline & $C-5^{\prime}$ & 143.6 & ${ }^{2} J=6.7$ & ---- \\
\hline & & & ${ }^{2} J=6.7$ & \\
\hline & Me-3' & 13.1 & ${ }^{1} J=126.9$ & 2.00 \\
\hline & Me-5' & 12.3 & ${ }^{1} j=129.2$ & 2.07 \\
\hline & $\mathrm{N}-1 "$ & -187.4 & & ---- \\
\hline & N-2" & -75.8 & & ---- \\
\hline & C-3" & 149.0 & ${ }^{2} J=6.4$ & ---- \\
\hline & & & ${ }^{2} J=6.4$ & \\
\hline Position & C-4" & 104.0 & ${ }^{1} J=172.4$ & 5.40 \\
\hline $2,3,6,7$ & & & ${ }^{3} J=3.2$ & \\
\hline & & & ${ }^{3} \mathrm{~J} 3.2$ & \\
\hline & Me-3" & 13.0 & ${ }^{1} J=126.9$ & 1.84 \\
\hline & Me-5" & 11.1 & ${ }^{1} J=128.9$ & 1.87 \\
\hline & C-1 & 138.5 & & ---- \\
\hline Naphthalene & $\mathrm{C}-2$ & 135.4 & & ---- \\
\hline & $\mathrm{C}-4 \mathrm{a}, 8 \mathrm{a}$ & 131.8 & & ---- \\
\hline
\end{tabular}

${ }^{\mathrm{a}}$ At $320 \mathrm{~K}$

For the assignment of the ${ }^{13} \mathrm{C}$ NMR signals to the quaternary naphthalene ring atoms $\mathrm{C}$ - 1 and $\mathrm{C}$ 2 (Table 1), we have used, as reference compounds, the benzene signals of hexakis(pyrazol-1yl)benzene $(\delta=136.6 \mathrm{ppm})$ and hexakis(3,5-dimethylpyrazol-1-yl)benzene $(\delta=138.8 \mathrm{ppm})$ $[5,6]$. Compared with benzene itself $(\delta=128.5 \mathrm{ppm})$, the effect of the six substituents on the ipso carbon are +8.1 and +10.3 ppm respectively. Applying these SCS values to naphthalene results in the following assignment (Scheme 2). 


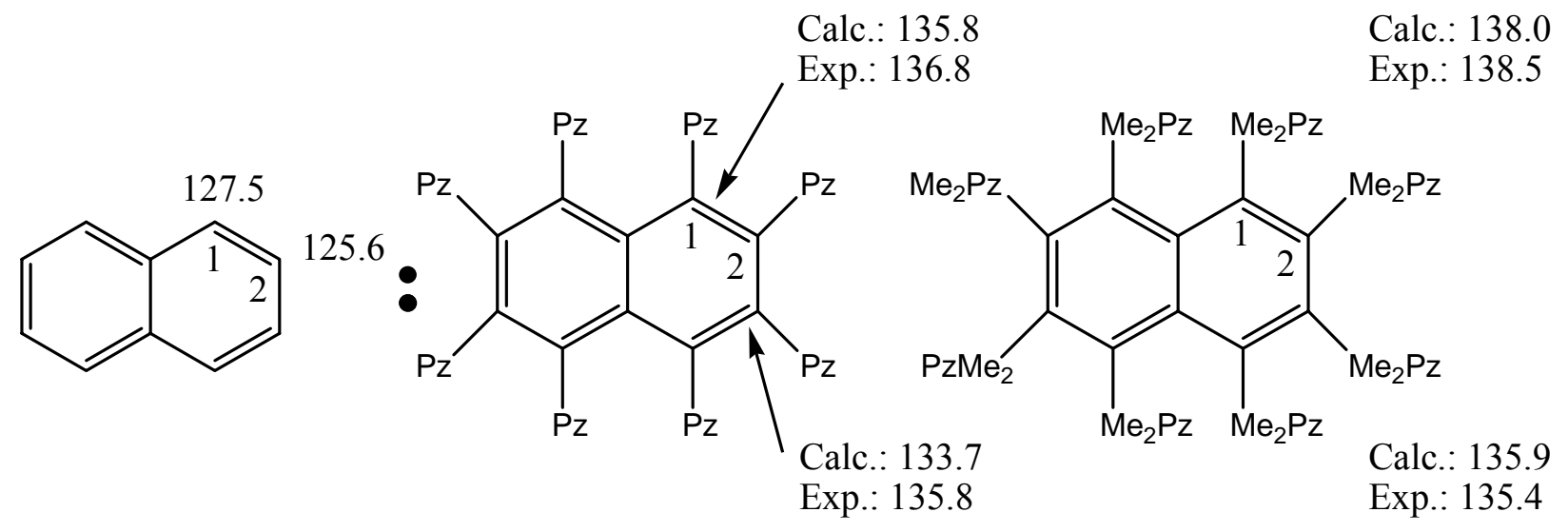

\section{Scheme 2}

Correlation experiments. We will discuss first the case of the octakis(pyrazol-1-yl)naphthalene $(\mathrm{OPzN})$. By means of a bidimensional $\left({ }^{1} \mathrm{H}-{ }^{1} \mathrm{H}\right)$ COSY experiment we have determined what protons $(\mathrm{H}-3, \mathrm{H}-4$ and $\mathrm{H}-5)$ belong to the pyrazole at position 1 and what to pyrazole at position 2. Then, another bidimensional experiment, $\left({ }^{1} \mathrm{H}_{-}{ }^{13} \mathrm{C}\right) \mathrm{HMQC}$, allows to assign the corresponding carbon atoms. To assign the signals to Pz-1 and Pz-2 we have used the observation that the three proton signals belonging to the same pyrazole at 7.31, 5.75 and 6.98 (see Table 1) were very broad at room temperature $(300 \mathrm{~K})$ and became well resolved at $320 \mathrm{~K}$. We have assumed that the pyrazole ring showing slow fluxionality are the more hindered pyrazoles at peri positions 1 , $4,5,8$.

In the case of the octakis(3,5-dimethylpyrazol-1-yl)naphthalene $\left(\mathrm{OMe}^{2} \mathrm{PzN}\right)$ the assignment of ${ }^{1} \mathrm{H}$ and ${ }^{13} \mathrm{C}$ signals was carried out through $\left({ }^{1} \mathrm{H}-{ }^{1} \mathrm{H}\right) \mathrm{COSY}$ and $\left({ }^{1} \mathrm{H}-{ }^{13} \mathrm{C}\right) \mathrm{HMQC}$ experiments. The quaternary carbon atoms, C-3', C-5', C-3" and C-5" were assigned using an $\left({ }^{1} \mathrm{H}_{-}{ }^{13} \mathrm{C}\right) \mathrm{HMBC}$ experiment. A NOESY experiment shows only one clear cross peak between the methyl groups at 2.00 and $2.07 \mathrm{ppm}$. Since these peaks belong to the same substituent, we assign them to the substituents at positions 1, 4, 5, 8 because the 3'-methyl at 2.00 (up) is close to the 5'-methyl at 2.07 ppm (down) in the peri positions.

${ }^{15} \mathrm{~N}$ NMRstudies 


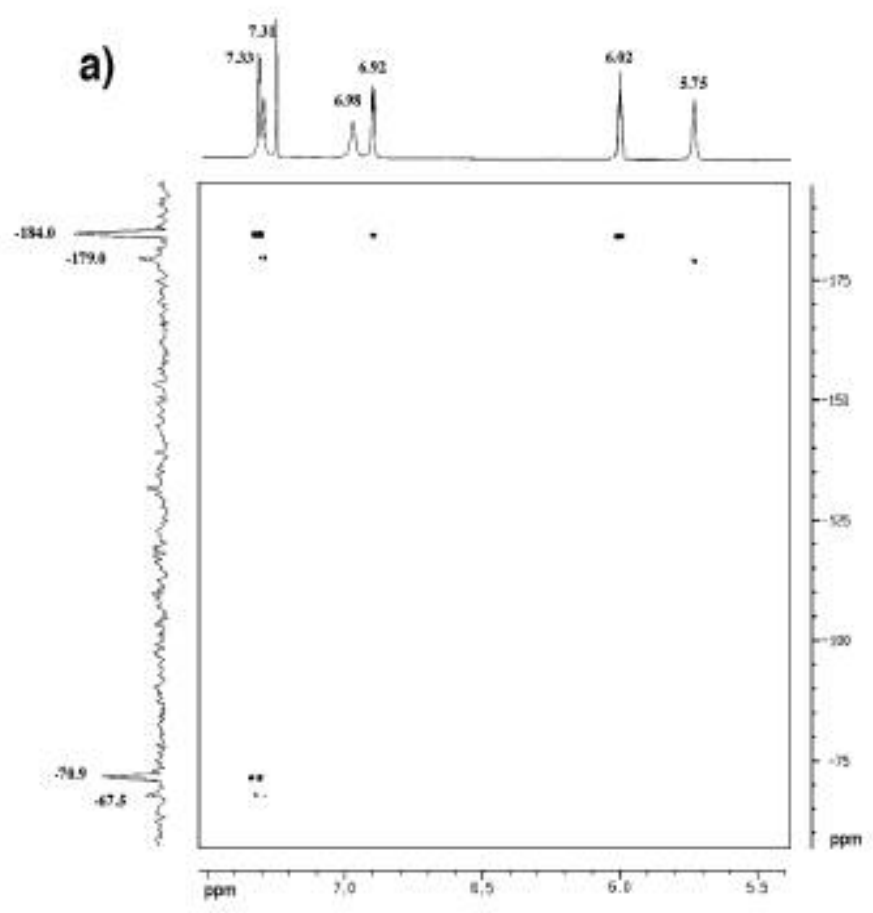




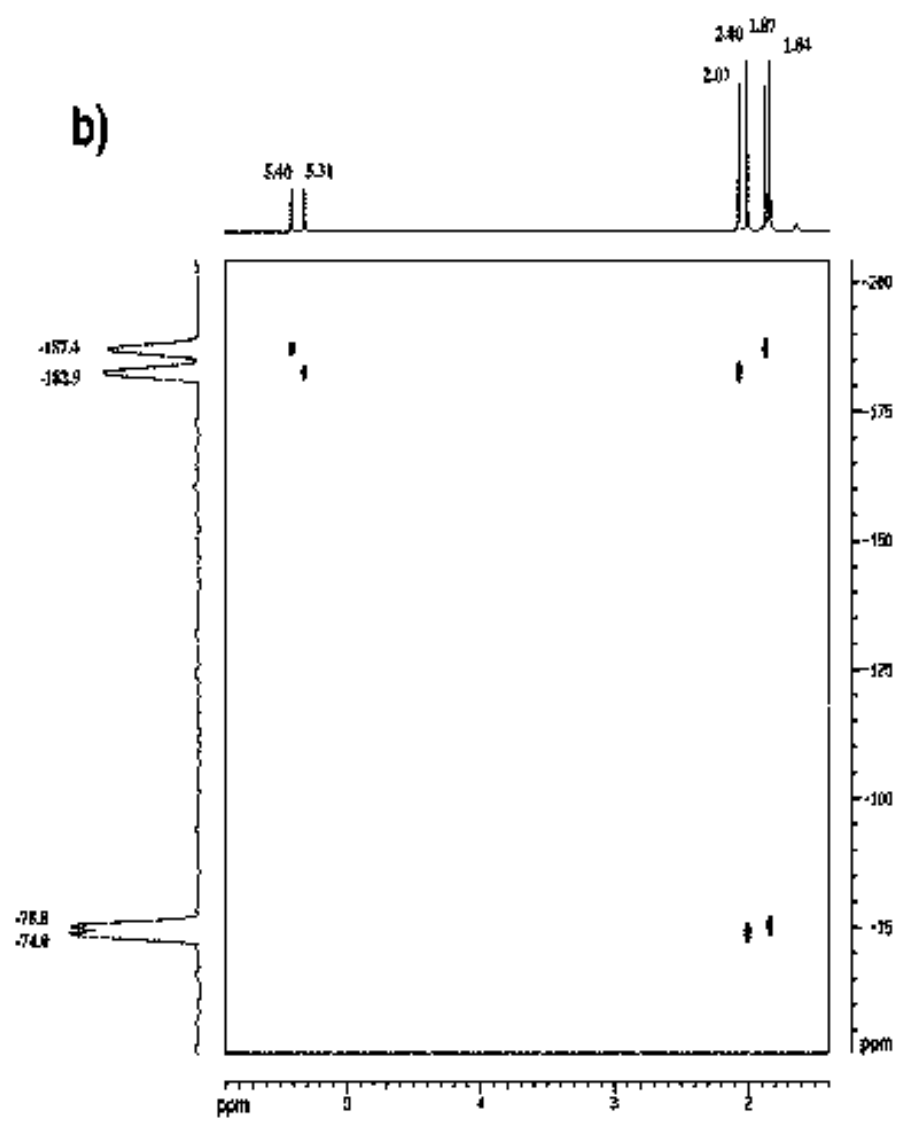

\section{Figure 1}

${ }^{1} \mathrm{H}-{ }^{15} \mathrm{~N}$ HMBC correlations: (a) OPzN, (b) $\mathrm{OMe}_{2} \mathrm{PzN}$.

The assignment of the nitrogen atoms to pyrazoles at positions 1 and 2 of the naphthalene ring was based on $\left({ }^{1} \mathrm{H}^{-15} \mathrm{~N}\right) \mathrm{HMBC}$ experiments; for $\mathrm{OPzN}$ the experiment was performed at $320 \mathrm{~K}$. The assignment of N-1 and N-2 for each pyrazole was made by analogy with the chemical shifts of 1-phenylpyrazole [8]. The results are reported in Table 1.

The fact that both $\mathrm{OPzN}$ and $\mathrm{OMe}_{2} \mathrm{PzN}$ show only a family of signals in ${ }^{1} \mathrm{H},{ }^{13} \mathrm{C}$ and ${ }^{15} \mathrm{~N}$ NMR is in contrast of what we have found in hexakis(pyrazol-1-yl) and hexakis(3,5-dimethylpyrazol-1yl) benzenes [5-7] were several conformers are generally seen. Although the aim of this paper is not related to the study of the conformational aspects of per(pyrazol-1-yl)naphthalenes, the simplicity of the ${ }^{1} \mathrm{H}$ and ${ }^{13} \mathrm{C}$ NMR spectra is indicative, in the case of OPzN, of a freedom of rotation of the eight residues and in the case of $\mathrm{OMe}_{2} \mathrm{PzN}$ of a conformation with the highest symmetry like the udududud one. 

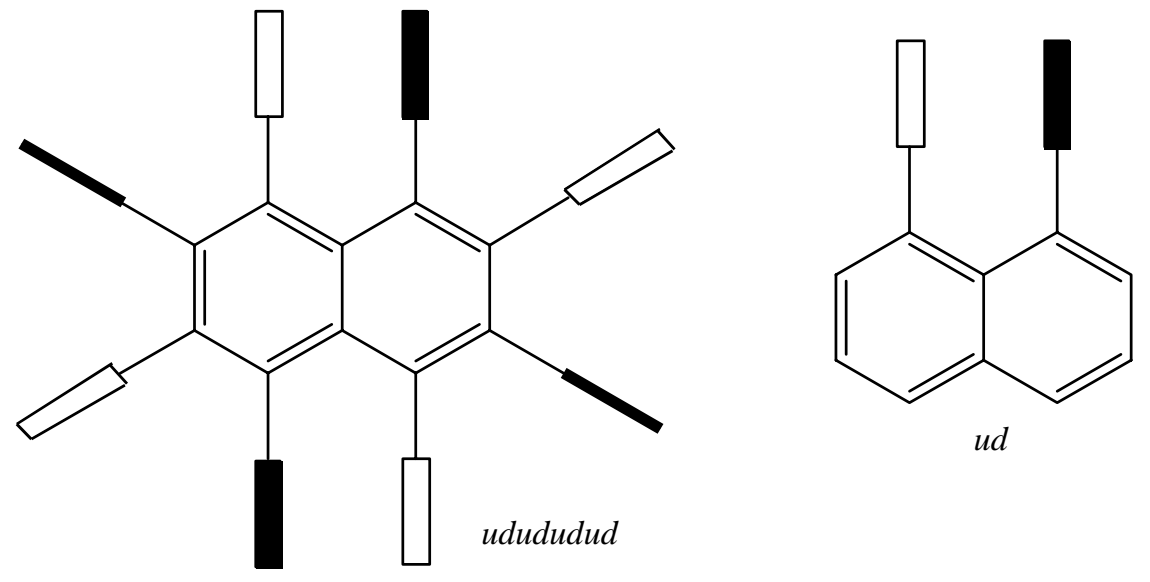

\section{Scheme 3}

In the case of 1,8-bis(1,2,3-triazol-1-yl)naphthalene it has been demonstrated by X-ray crystallography that the substituents adopt an ud conformation $[9,10]$. 
Absorption and Emission Spectra
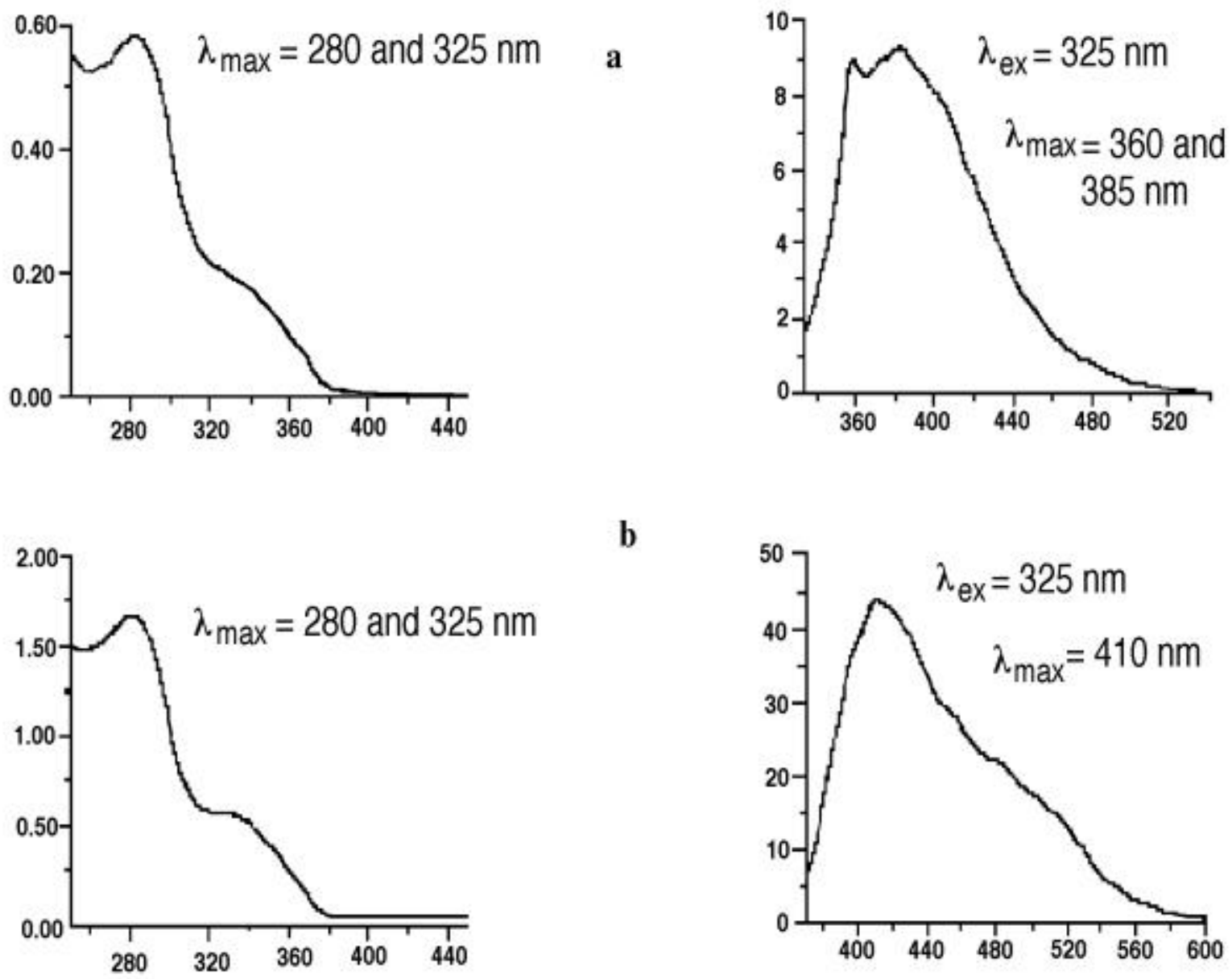

b

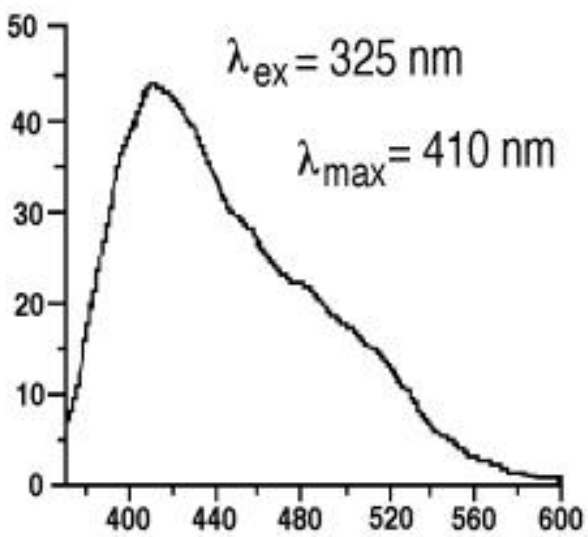

Figure 2. Absorption and emission spectra of $\mathrm{OPzN}$ in (a) ethanol and (b) in ethyl acetate. 


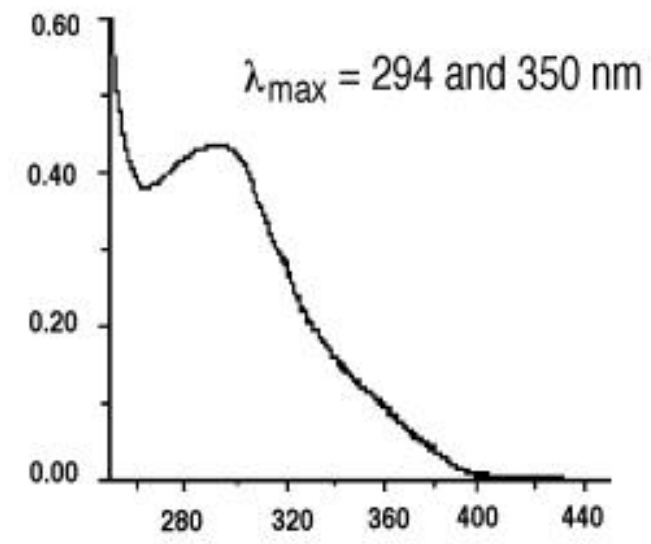

a
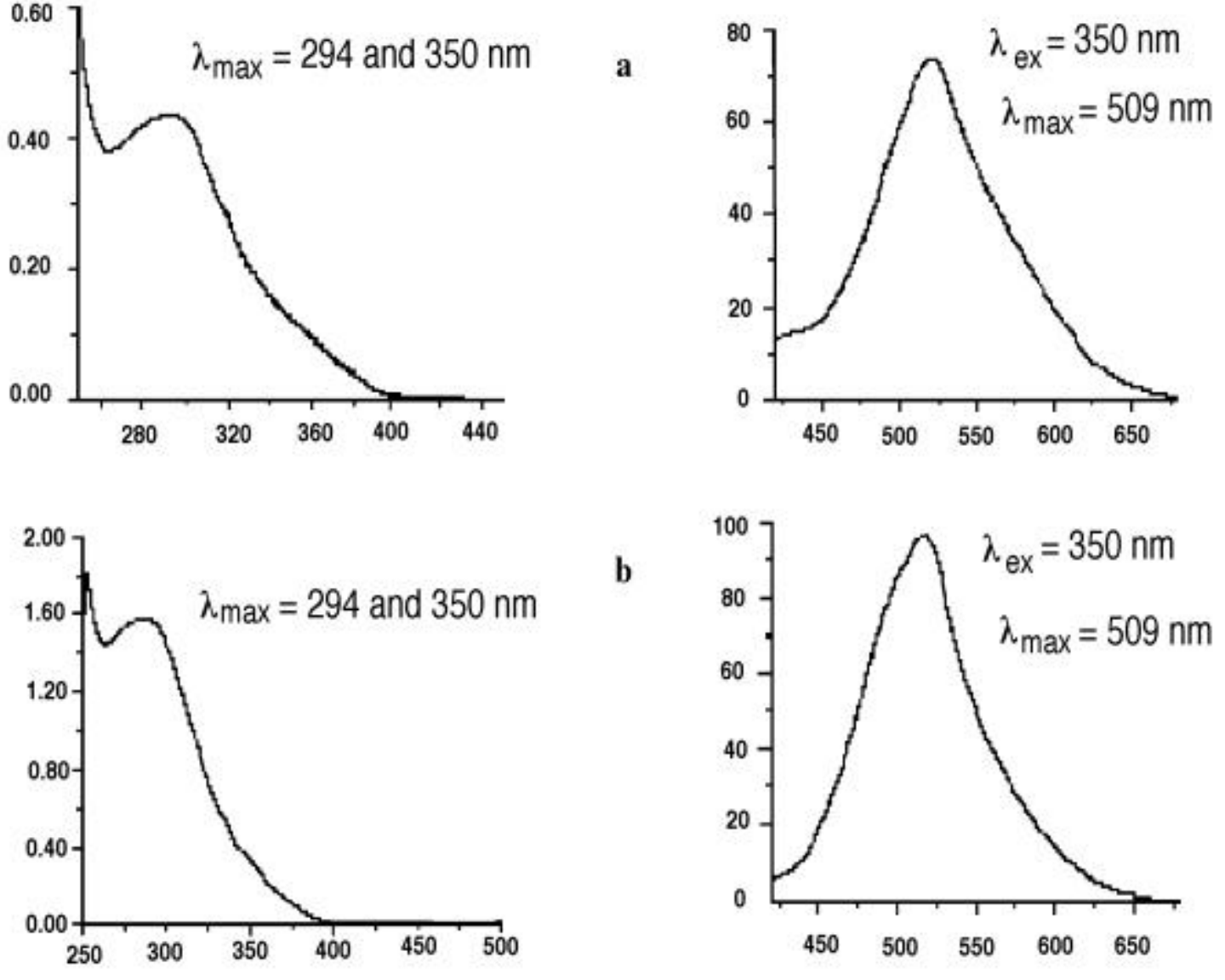

Figure 3. Absorption and emission spectra of $\mathrm{OMe}_{2} \mathrm{PzN}$ (a) in ethanol and (b) in ethyl acetate.

Absorption spectra for $\mathrm{OPzN}$ and $\mathrm{OMe}_{2} \mathrm{PzN}$ in ethanol and ethyl acetate are shown in Figures 2 and 3, respectively. OPzN exhibits an absorption band centered at $280 \mathrm{~nm}$ which corresponds to naphthalene (this compound displays a very structured absorption band centered at this wavelength [11]), with a red shifted shoulder around $325 \mathrm{~nm}$ probably as a consequence of the substitution in the aromatic ring. In the $\mathrm{OMe}_{2} \mathrm{PzN}$ spectra the main absorption is centered around $294 \mathrm{~nm}$ with an absorption tail which extends above $400 \mathrm{~nm}$.

Fluorescence spectra of both $\mathrm{OPzN}$ and $\mathrm{OMe}_{2} \mathrm{PzN}$ in the same solvents are also shown in Figures 2 and 3. When OPzN in ethanol is excited at $325 \mathrm{~nm}$ it presents a broad structured 
emission with maxima centered at $360 \mathrm{~nm}$ and $385 \mathrm{~nm}$ while in ethyl acetate it displays a red shifted broad and structureless fluorescence band centered around $410 \mathrm{~nm}$. Again the $\mathrm{OMe}_{2} \mathrm{PzN}$ exhibits only a red shifted structureless emission band around $509 \mathrm{~nm}$ in both solvents.

Examination of the spectra of differently substituted derivatives of naphthalene indicates that when substitution increases, both red shift and broadening of the vibrational fine structure of the absorption and emission bands occurred, probably as a consequence of the loss of planarity in the naphthalene chromophore as well as the increase in rotational and conformational structures of these substituted derivatives [3,11]. It can be concluded that substitution on naphthalene shifts the absorption and fluorescence bands of these derivatives to longer wavelengths, indicating that substitution has a greater effect than the nature of the substituent itself in these highly substituted naphthalene derivatives.

\section{Experimental Section}

General Procedures. Melting points were determined in a microscope hot stage apparatus and on a SEIKO DSC 220C instrument. Column chromatography was performed on silica gel Merck 60 (70-230 mesh) using the appropriate eluent. ${ }^{1} \mathrm{H}$ and ${ }^{13} \mathrm{C}-\mathrm{NMR}$ spectra in solution were recorded on a Bruker DRX 400 at 400.13 and $100.62 \mathrm{MHz}$, respectively. The assignments are based on NMR experiments with pulse field gradients: $\left({ }^{1} \mathrm{H}_{-}{ }^{1} \mathrm{H}\right) \mathrm{COSY},\left({ }^{1} \mathrm{H}_{-}{ }^{13} \mathrm{C}\right) \mathrm{HMQC},\left({ }^{1} \mathrm{H}-\right.$ $\left.{ }^{13} \mathrm{C}\right) \mathrm{HMBC}$ and $\left({ }^{1} \mathrm{H}_{-}{ }^{15} \mathrm{~N}\right) \mathrm{HMBC}$.

Chemical shifts $(\delta)$ are given from TMS for ${ }^{1} \mathrm{H}$ and ${ }^{13} \mathrm{C}$ NMR and from external (capillary) nitromethane for ${ }^{15} \mathrm{~N}$ NMR. Infrared spectra were recorded on a Philips PU 9714 spectrometer and mass spectra were performed on a VG AutoSpec spectrometer using fast-atom bombardment $(\mathrm{FAB}+)$ and matrix meta-nitrobenzyl alcohol (NBA).

\section{Conclusions}

Absorption spectra of $\mathrm{OPzN}$ and $\mathrm{OMe}_{2} \mathrm{PzN}$ (in EtOH and EtOAc) present two bands each, around 280 and $325 \mathrm{~nm}$ and 294 and $350 \mathrm{~nm}$, respectively. Emission spectra in EtOAc for both compounds exhibit a broad, structureless blue fluorescence centered at around $410 \mathrm{~nm}$ for OPzN and $509 \mathrm{~nm}$ for $\mathrm{OMe}_{2} \mathrm{PzN}$, naphthalene itself having a very structured emission beginning at 320 nm. 
Pyrazolyl and 3,5-dimethylpyrazolyl substitution on naphthalene shifts the fluorescence of these derivatives $\mathrm{OPzN}$ and $\mathrm{OMe}_{2} \mathrm{PzN}$ to longer wavelengths, therefore fulfilling the preliminary conditions to study their electrogenerated chemiluminescence properties. To go further on, more soluble compounds have to be prepared, for instance, using pyrazoles with long alkyl chains at position 4.

\section{Acknowledgements}

Thanks are given to the Ministry of Education and Culture of Spain (DGES, project number PB96-0001-CO3) and to 'Comunidad de Madrid' of Spain (project number 07N/0001/1999) for economic support.

\section{References}

1. Lee, S. K.; Richter, M. M.; Strekowski, L.; Bard, A. J. Anal. Chem. 1997, 69, 4126.

2. Richter, M. M.; Bard, A. J.; Kim, W.; Schmehl, R. H. Anal. Chem. 1998, 70, 310.

3. Debad, J. D.; Lee, S. K.; Qiao, X.; Pascal, Jr.; R. A.; Bard, A. J. Acta Chem. Scand. 1998, $52,45$.

4. Claramunt, R. M.; Elguero, J.; Escolastico, C.; Fernandez-Castano, C.; Foces-Foces, C.; Llamas-Saiz, A. L.; Santa Maria, M. D. Targets in Heterocyclic Systems. Synthesis, Reactions and Properties. Editors. O. A. Attanasi and D. Spinelli. 1997,1.

5. Foces-Foces, C.; Llamas-Saiz, A. L.; Claramunt, R. M.; Jagerovic, N.; Jimeno, M. L.; Elguero, J. J. Chem. Soc. Perkin Trans 2 1995, 1359.

6. Foces-Foces, C.; Llamas-Saiz, A. L.; Escolastico, C.; Claramunt, R. M.; Elguero, J. J. Phys. Org. Chem. 1996, 9, 137.

7. Foces-Foces, C.; Llamas-Saiz, A. L.; Fernandez-Castano, C.; Claramunt, R. M.; Escolastico, C.; Lavandera, J. L.; Santa-Maria, M. D.; Jimeno, M. L.; Elguero, J. . J. Chem. Soc. Perkin Trans 2 1997, 2173.

8. Claramunt, R. M.; Sanz, D.; Lopez, C.; Jimenez, J. A.; Jimeno, M. L.; Elguero, J.; Fruchier, A. Magn. Reson. Chem. 1997, 35, 35.

9. Nagawa, Y.; Goto, M.; Honda, K.; Nakanishi, H. Acta Crystallogr. Sect. C 1986, 42, 478.

10. Nagawa, Y.; Goto, M.; Honda, K.; Nakanishi, H. Bull. Chem. Soc. Jpn. 61 (1988) 3553. 
11. Berlman, J. B. Handbook of Fluorescence Spectra of Aromatic Molecules, 2nd edn., Academic Presss, New York, 1971. 